\title{
The Affordable Care Act Medicaid Expansion Positively Impacted Community Health Centers and Their Patients
}

\author{
Alyssa Shell Tilhou, MD, $P h D^{1,2}$ (1), Nathalie Huguet, $P h D^{7}$, \\ Jennifer DeVoe, MD, DPhil, MPhil', and Heather Angier, $\mathrm{PhD}, \mathrm{MPH}^{1}$ \\ 'Department of Family Medicine, Oregon Health \& Science University, Portland, OR, USA; ${ }^{2}$ Department of Family Medicine and Community Health, \\ University of Wisconsin School of Medicine and Public Health, Madison, WI, USA.
}

Community health centers (CHCs) provide primary care for underserved children and adults. The Patient Protection and Affordable Care Act (ACA) aimed to strengthen the $\mathrm{CHC}$ network by increasing federal funds and expanding Medicaid eligibility. The ACA also aimed to boost preventive and mental health services and to reduce health and healthcare disparities. Here, we summarize our results to-date as experts in investigating the impact of ACA Medicaid expansion on $\mathrm{CHCs}$ and the patients they serve. We found the ACA Medicaid expansion increased access to care and preventive services, primarily in Medicaid expansion states. Rates of physical and mental health conditions rose substantially from pre- to postACA in expansion states, suggesting underdiagnosis preACA. Disparities in health insurance coverage by race/ethnicity decreased at CHCs, yet some remain. These findings indicate that the ACA Medicaid expansion significantly helped $\mathrm{CHCs}$ and patients. Insurance expansion buoyed CHCs' financial viability by increasing reimbursement. Therefore, the ACA Medicaid expansion enhanced the health of underserved patients and repeal would jeopardize these advances for CHCs and their patients.

KEYWORDS: community health centers; Patient Protection and Affordable Care Act; uninsured; healthcare disparities; health care reform.

J Gen Intern Med 35(4):1292-5

DOI: $10.1007 / \mathrm{s} 11606-019-05571-\mathrm{w}$

(c) Society of General Internal Medicine 2019

\section{INTRODUCTION}

The community health center $(\mathrm{CHC})$ program was created in 1965 to provide "comprehensive, high-quality preventive and primary health care" to vulnerable populations regardless of their ability to pay. ${ }^{1}$ Since inception, the program expanded to provide services to over 28 million patients as of 2019 including one in six Medicaid beneficiaries, one in three individuals below the poverty line, and one in four rural Americans. ${ }^{2}$

The successes of the $\mathrm{CHC}$ program exist even as their patients face significant health challenges. $\mathrm{CHC}$ patients tend to be sicker than other low-income patients, reporting higher rates of chronic conditions such as diabetes, hypertension, and

Received June 17, 2019

Accepted November 20, 2019

Published online January 2, 2020 asthma. ${ }^{3}$ They also experience difficulty accessing specialty services and diagnostic procedures. ${ }^{3}$ CHC patients are also more likely to be unemployed and uninsured, have lowincome, and be from a nonwhite racial/ethnic group compared with patients seen in non-CHC clinics. ${ }^{3}$ These socioeconomic and demographic factors compound poor health status.

In addition to $\$ 11$ billion in direct funding, ${ }^{1}$ the Patient Protection and Affordable Care Act (ACA) indirectly channeled funding into the health center program through health insurance coverage expansions by expanding Medicaid eligibility to adults in households earning $\leq 138 \%$ of the federal poverty level (FPL). ${ }^{4}$ All told, overall CHC patient panels grew $10 \%$ and the percentage of $\mathrm{CHC}$ patients with insurance coverage increased to over $75 \%{ }^{4}$ The ACA Medicaid eligibility expansion was the major driver of these changes. In addition, the ACA was designed to increase the quality and scope of care provided to patients at CHCs and to reduce health disparities. For example, the ACA aimed to improve access to preventive care and mental health services and prohibited insurance companies from discriminating against patients with pre-existing conditions. ${ }^{5}$

Despite admirable goals, the ACA continues to receive significant criticism. ${ }^{6}$ Critics emphasize excessive costs to the system, employers, and individuals. ${ }^{7}$ Some also make claims of lack of justice: the healthy and young should not have to pay for the sick and old. ${ }^{7}$ From a consumer perspective, shifts in the healthcare marketplace since ACA implementation present new challenges. For example, several national insurers exited the market due to financial losses, which likely limited consumer health insurance choices. ${ }^{8}$ From a patient perspective, extra funding to support behavioral and mental health has not overcome workforce shortages. ${ }^{9}$

Given these criticisms, it is imperative to evaluate the ACA's impact on CHCs and their patients. Exploring this impact can offer patients, providers, and policymakers evidence of how ACA policies, especially the ACA Medicaid expansion, positively impacted many of the nation's most vulnerable populations to support advocacy for its continuation. Thus, in this perspective, we summarize our results todate as experts in investigating the impact of ACA Medicaid expansion on CHCs and the patients they serve.

To assess the impact of the ACA, our team utilized the Accelerating Data Value Across a National Community 
Health Center Network (ADVANCE) clinical data research network data of PCORNet. ${ }^{10}$ ADVANCE contains patientlevel electronic health record data from $\mathrm{CHCs}$ in states that expanded Medicaid as well as those that did not. As of 2019, 14 states had decided not to implement Medicaid expansion following the Supreme Court's decision obviating the legal requirement. ${ }^{11,12}$ With these data from ADVANCE, we were able to investigate the "natural experiment" of some states expanding Medicaid while others did not using differencein-difference analyses. ${ }^{13}$

\section{HEALTH INSURANCE COVERAGE INCREASED}

While CHCs are committed to providing care to all patients, they rely on insurance reimbursement to supplement federal funding. ${ }^{4}$ The ACA Medicaid expansion, therefore, positively impacted CHCs by increasing the percentage of their patients with insurance coverage. ${ }^{14-16}$ The improvement was greater in states that expanded Medicaid compared with states that did not. ${ }^{14-16}$ In demonstration, expansion states experienced a significant surge $(60 \%)$ in Medicaid-insured visits but remained unchanged in nonexpansion states. ${ }^{16}$ With a rise in Medicaid coverage came increased access: for instance, $\mathrm{CHCs}$ in expansion states experienced significant growth in new patient and preventive visit rates as well as an increase in visits for ancillary services (e.g., labs, X-rays), while rates in nonexpansion states remained unchanged. ${ }^{14}$

Findings of increased coverage and visit rates suggest that ACA Medicaid expansion boosted primary care access for a large proportion of patients seeking care at $\mathrm{CHCs}$ in expansion states. These changes were good for patients: increased access to care means more opportunities for diagnosis and management of mental and physical health conditions. ${ }^{17}$ These changes were also good for CHCs: added insurance coverage means more patients able to pay for services creating more opportunities to expand service provision to all patients. In support, a recent survey of CHCs by the Commonwealth Fund demonstrated increased perceived financial stability among centers in expansion states. ${ }^{9}$ In this way, the ACA Medicaid expansion enhanced $\mathrm{CHCs}$ ' financial viability by augmenting reimbursement.

Repeal or modification of the ACA Medicaid expansion would risk these advances in access and jeopardize patients' health. Without coverage, patients' access to regular care and preventive services will decline. ${ }^{18}$ With increased uninsurance, CHCs could lose access to an important source of revenue and face increased financial jeopardy. This potential risk is exacerbated because CHCs serve socially and medically complex patients, for whom care is expensive.

Decreased access to care with repeal of the ACA Medicaid expansion could also shift care back to the emergency department (ED) and raise costs. Research shows that ED visits go up when regular care is disrupted, ${ }^{19}$ while ED visits go down with increased care continuity. ${ }^{20}$ Access to $\mathrm{CHCs}$, specifically, is associated with fewer uninsured visits to the ED. ${ }^{21}$ Care for the uninsured in the ED is costly, an expense borne by other patients, payers, and the community. ${ }^{21}$

\section{ACCESS TO ESSENTIAL PREVENTIVE SERVICES IMPROVED}

Preventive care is one of the core services provided at $\mathrm{CHCs}$ and an important part of staying healthy. ${ }^{2} \mathrm{CHCs}$ provide high levels of preventive services and in many cases exceed other primary care settings. ${ }^{2}$ Yet, vulnerable patients face barriers to receiving recommended services. Uninsured patients are particularly likely to lack receipt of important preventive measures. ${ }^{18}$

The ACA Medicaid expansion was associated with growth in the provision of preventive services, especially in states that chose to expand Medicaid. For example, Hoopes et al. found a $41 \%$ surge in preventive visits in expansion states but no significant increase in nonexpansion states. ${ }^{14}$ Huguet et al. found a $15 \%$ increase in preventive medicine visits and an $11 \%$ rise in immunization rates in expansion states from preto post-ACA. ${ }^{16}$ Huguet et al. also showed a higher rate ratio for glycated hemoglobin screening post-ACA for patients without diabetes and those with pre-diabetes in expansion states. $^{22}$ These findings suggest that the ACA Medicaid expansion had a positive impact on receipt of preventive services in CHCs. Indeed, research previously demonstrated that patients' access to regular care and preventive services declines without coverage. ${ }^{18,23}$ In this way, repeal of ACA Medicaid expansion could reverse advances made in improving access to preventive services.

\section{PRE-EXISTING HEALTH CONDITIONS WERE DIAGNOSED}

CHCs care for a large proportion of patients with comorbidities. ${ }^{2}$ Historically, patients with pre-existing conditions faced high premiums or coverage denial limiting affordability and access to care. ${ }^{24}$ Huguet et al. found a large increase in the prevalence of pre-existing conditions from pre- to post-ACA among $\mathrm{CHC}$ patients residing in Medicaid expansion states who were uninsured in the pre-period. ${ }^{25,26}$ These findings suggest that a large proportion of conditions were underdiagnosed and undertreated pre-ACA Medicaid expansion due to limited access. Underdiagnosis of chronic conditions has significant health implications: the detection of chronic conditions at the earliest stage possible is critically important to ensure appropriate treatment, decrease risk of complications, and reduce associated costs. ${ }^{17}$ These trends also carry significant consequences for $\mathrm{CHCs}$ on a clinic level. Care of patients with delayed diagnoses and comorbidities, particularly if uncontrolled, is expensive. ${ }^{27}$ While a significant portion of health center funding is through federal grants, the majority comes from health insurance reimbursement. ${ }^{4}$ 
Consequently, interventions that increase health insurance access enhance CHC viability. As a result, repeal of the ACA Medicaid expansion would pose great consequences for patients and $\mathrm{CHCs}$ by compromising access to healthcare and $\mathrm{CHC}$ viability. ${ }^{17}$

\section{MENTAL HEALTH PARITY MATTERS}

Behavioral health and psychiatric care are central components of $\mathrm{CHC}$ services despite historic underfunding. ${ }^{1}$ Huguet et al. assessed the prevalence of pre-existing conditions post-ACA Medicaid expansion among patients who had no insurance coverage in the pre-ACA period, and demonstrated a high prevalence of mental health diagnoses among $\mathrm{CHC}$ patients in both states that expanded Medicaid and those that chose not to. ${ }^{26,}{ }^{28}$ Mental health disorders were shown to be the most common conditions among $\mathrm{CHC}$ patients who gained Medicaid or private insurance following the ACA Medicaid expansion. $^{26,28}$ Specifically, the diagnosis with the highest percent increase from pre- to post-ACA Medicaid expansion was a substance use disorder. ${ }^{26}$ The data also showed that nonHispanic Black and Hispanic patients experienced greater increases in these diagnoses pre- to post-ACA Medicaid expansion. In these groups, diagnosis of substance use disorders more than doubled. ${ }^{26}$

Patients with mental health diagnoses would face unique consequences following repeal of the ACA Medicaid expansion. Most $\mathrm{CHCs}$ in expansion states responded to high rates of mental health diagnoses by increasing mental health and substance use services following ACA implementation. ${ }^{4}$ Without another source of funding, these services would be in jeopardy of closing or experiencing significant cutbacks.

\section{HEALTH DISPARITIES HAVE BEEN REDUCED}

The CHC program was originally created to help reduce health disparities due to income, education, and race/ethnicity. ${ }^{2}$ The ACA also aimed to reduce health disparities. For example, Cole et al. found that the ACA Medicaid expansion augmented preventive service receipt in rural compared with urban CHCs within expansion states. ${ }^{29}$ Angier et al., however, demonstrated that the ACA Medicaid expansion helped reduce but did not eliminate healthcare disparities in CHCs. ${ }^{30}$ For example, CHCs in expansion states experienced a large increase in Medicaid-insured visits for all race/ethnicity groups, but the disparities between the groups did not improve. ${ }^{30,}{ }^{31}$ For patients with diabetes, Medicaid-insured visits were $17 \%$ higher for Hispanics in expansion states compared with nonHispanic whites, yet the relative disparity in uninsured visit rates actually increased $94 \%$ in expansion states. ${ }^{31}$ This pattern reflects a large population of Hispanic patients who either cannot afford or cannot access health insurance options due to income or citizenship.
Residual disparities in health insurance coverage challenge $\mathrm{CHC}$ financial viability because $\mathrm{CHCs}$ provide care for a disproportionate share of uninsured patients and diverse racial and ethnic groups. Disparities in insurance status also pose increased health challenges to already vulnerable populations. While the ACA Medicaid expansion helped minimize some disparities, additional efforts are needed to improve access and utilization in $\mathrm{CHCs}$ across racial and ethnic groups. With ACA provision changes, progress made toward mitigating these disparities would be lost.

\section{CONCLUSION}

Research from CHCs showed that the ACA Medicaid expansion increased health insurance coverage, boosted provision of preventive services, increased access to care for $\mathrm{CHC}$ patients including those with pre-existing conditions and mental health diagnoses, and reduced some racial/ethnic disparities. In addition, detection and treatment of chronic physical and mental health conditions increased as insurance coverage expanded. These patterns were particularly apparent in states that expanded Medicaid. We know of no research contradicting the positive findings highlighted in this commentary.

These results carry important implications for the primary care safety net. Even within the CHC system, which is designed to care for uninsured patients, Medicaid expansion increased access and revealed underdiagnosis and undertreatment of chronic physical and mental health conditions. Repeal of the ACA Medicaid expansion would significantly jeopardize health insurance coverage, health care access, and the health of many underserved patients seen in CHCs.

Corresponding Author: Alyssa Shell Tilhou, $M D, P h D$; Department of Family Medicine and Community Health University of Wisconsin School of Medicine and Public Health, Madison, WI, USA (e-mail: alyssatilhoumd@gmail.com).

Funding Information There are no additional contributors, funders, or prior presentations related to this work. This work was supported by the Agency for Healthcare Research and Quality (grant number R01HS024270), by the National Cancer Institute (grant number R01CA204267), and by the National Health, Lung, and Blood Institute (grant number R01HL136575). This publication was also supported by Cooperative Agreement Number U18DP006116 jointly funded by the U.S. Centers for Disease Control and Prevention and the National Institute of Diabetes and Digestive and Kidney Disease, and Patient-Centered Outcomes Research Institute

\section{Compliance with Ethical Standards:}

Conflict of Interest: The authors declare that they do not have a conflict of interest.

\section{REFERENCES}

1. Health Resources and Services Administration. The Affordable Care Act and health centers. U.S. Department of Health and Human Services 
https://www.hrsa.gov/sites/default/files/about/news/2012tables/ healthcentersacafactsheet.pdf. Accessed February 24, 2019.

2. Community Health Center Chartbook. National Association of Community Health Centers; 2019. http://www.nachc.org/wp-content/uploads/ 2019/01/Community-Health-Center-Chartbook-FINAL-1.28.19.pdf. Accessed April 27, 2019.

3. Shin P, Alvarez C, Sharac J, et al. A profile of community health center patients: implications for policy. Issue brief. The Henry J. Kaiser Family Foundation; 2013:17. https://kaiserfamilyfoundation.files.wordpress. com/2013/12/8536-profile-of-chc-patients.pdf. Accessed December 5, 2018.

4. Paradise J, Rosenbaum S, Markus A, Sharac J, Tran C, Reynolds D. Community health centers: recent growth and the role of the ACA. The Henry J. Kaiser Family Foundation; 2017.

5. Summary of the Affordable Care Act. Henry J Kaiser Family Foundation; 2013. https://www.kff.org/health-reform/fact-sheet/summary-of-theaffordable-care-act/. Accessed April 25, 2019

6. Jost T. Examining The House Republican ACA Repeal And Replace Legislation | Health Affairs. Health Aff Blog ACA. March 2017. https:// www.healthaffairs.org/do/10.1377/hblog20170307.059064/full/. Accessed December 31, 2018.

7. Ho v. Refinement of the Affordable Care Act. Annu Rev Med. 2018;69(1):19-28.

8. Garthwaite C, Graves JA. Success and failure in the insurance exchanges. N Engl J Med. 2017;376(10):907-910.

9. Lewis C, Coleman A, Abrams M, Doty M. Role of Medicaid Expansion Care Delivery Community Health Centers. Commonwealth Fund; 2019. https://www.commonwealthfund.org/publications/issue-briefs/2019/ apr/role-medicaid-expansion-care-delivery-FQHCs. Accessed August 31, 2019.

10. ADVANCE. http://advancecollaborative.org/. Accessed September 20, 2019.

11. Supreme Court of the United States. National Federation of Independent Business v Sebelius. 2012; 2012:193.

12. The Henry J Kaiser Family Foundation. Status of state action on the Medicaid expansion decision. 2019; https://www.kff.org/health-reform/ state-indicator/state-activity-around-expanding-medicaid-under-the-affordable-care-act/. Accessed September 20, 2019.

13. Lechner M. The estimation of causal effects by difference-in-difference methods. Found Trends ${ }^{\circledR}$ Econ. 2011;4(3): 165-224.

14. Hoopes MJ, Angier H, Gold R, et al. Utilization of community health centers in Medicaid expansion and non-expansion states, 2013-2014. J Ambulatory Care Manage. 2016;39(4):290.

15. Angier H, Hoopes $\mathbf{M}$, Gold $\mathbf{R}$, et al. An early look at rates of uninsured safety net clinic visits after the Affordable Care Act. Ann Fam Med. 2015;13(1):10-16.

16. Huguet N, Hoopes MJ, Angier H, Marino M, Holderness H, DeVoe JE. Medicaid expansion produces long-term impact on insurance coverage rates in community health centers. J Prim Care Community Health. $2017 ; 8(4): 206-212$
17. Hoffman C, Paradise J. Health insurance and access to health care in the United States. Ann N Y Acad Sci. 2008;1136(1):149-160.

18. DeVoe JE, Fryer GE, Phillips R, Green L. Receipt of preventive care among adults: insurance status and usual source of care. Am J Public Health. 2003;93(5):786-791

19. Weber EJ, Showstack JA, Hunt KA, Colby DC, Callaham ML. Does lack of a usual source of care or health insurance increase the likelihood of an emergency department visit? Results of a national population-based study. Ann Emerg Med. 2005;45(1):4-12.

20. Petersen LA, Burstin HR, O'Neil AC, Orav EJ, Brennan TA. Nonurgent emergency department visits: the effect of having a regular doctor. Med Care. 1998;36(8): 1249-1255.

21. Rust G, Baltrus $\mathbf{P}$, Ye J, et al. Presence of a community health center and uninsured emergency department visit rates in rural counties. J Rural Health. 2009;25(1):8-16.

22. Huguet N, Springer R, Marino $\mathbf{M}$, et al. The impact of the Affordable Care Act (ACA) Medicaid expansion on visit rates for diabetes in safety net health centers. J Am Board Fam Med. 2018;31(6):905-916.

23. Marino M, Bailey SR, Gold R, et al. Receipt of preventive services after Oregon's randomized Medicaid experiment. Am J Prev Med. 2016;50(2):161-170.

24. Harrington SE. The health insurance reform debate. J Risk Insur. 2010;77(1):5-38.

25. Huguet N, Valenzuela S, Marino $\mathbf{M}$, et al. Following uninsured patients through Medicaid expansion: healthcare utilization and diagnosed conditions. Ann Fam Med. 2019;17(3).

26. Huguet $\mathbf{N}$, Angier $\mathbf{H}$, Hoopes $\mathbf{M}$, et al. Assessing the prevalence of preexisting conditions among community health center patients. J Am Board Fam Med. 2019:32;883-889.

27. Egede LE, Bishu KG, Walker RJ, Dismuke CE. Impact of diagnosed depression on healthcare costs in adults with and without diabetes: United States, 2004-2011. J Affect Disord. 2016;195:119-126.

28. Angier $\mathbf{H}$, Huguet $\mathbf{N}$, Hoopes $\mathbf{M}$, et al. Prevalence and type of preexisting conditions before and after the Affordable Care Act among vulnerable populations. In: 46th Annual Meeting of the North American Primary Care Research Group. Chicago, IL; 2018.

29. Cole MB, Wright B, Wilson IB, Galárraga O, Trivedi AN. Medicaic expansion and community health centers: care quality and service use increased for rural patients. Health Aff (Millwood). 2018;37(6):900-907.

30. Angier $\mathbf{H}$, Hoopes $\mathbf{M}$, Marino $\mathbf{M}$, et al. Uninsured primary care visit disparities under the Affordable Care Act. Ann Fam Med. 2017;15(5):434442.

31. Angier H, Ezekiel-Herrera D, Marino M, et al. An observational study to assess racial/ethnic disparities in health insurance for a population of patients with diabetes after Medicaid expansion. J Health Care Poor Underserv. In press.

Publisher's Note: Springer Nature remains neutral with regard to jurisdictional claims in published maps and institutional affiliations. 